\title{
Polyamide-rubber blends: microscopic studies of the deformation zone
}

\author{
H. Janik \\ Technical University of Gdansk, 80-952 Gdansk, Poland \\ and R. J. Gaymans* \\ University of Twente, PO Box 217, 7500 AE Enschede, The Netherlands \\ and K. Dijkstra \\ DSM Research, PO Box 18,6160 MD Geleen. The Netherlands \\ (Received 25 January 1995; revised 19 May 1995)
}

\begin{abstract}
The morphology of injection moulded samples of polyamide-polybutadiene blends (85.15) with an average particle size of $0.3 \mu \mathrm{m}$ was studied. The samples were fractured in a notched tensile test at crosshead speeds of $10^{-4}$ and $1 \mathrm{~m} \mathrm{~s}^{-1}$ and the structure of the deformation zone was studied using various techniques: polarized light microscopy, scanning electron microscopy, transmission electron microscopy on stained cut samples and carbon replicas, and selected area electron diffraction transmission electron microscopy. The deformation zone of samples tested at $10^{-4} \mathrm{~m} \mathrm{~s}^{-1}$ was found to consist of two layers. Far from the fracture surface a layer was observed with more or less round cavities and with cavities in the rubber particles, while near the fracture surface a layer with strongly deformed cavities (length/diameter ratio of 5-10) could be seen. In the samples tested at $1 \mathrm{~m} \mathrm{~s}^{-1}$ the deformation zone was found to have three layers. In addition to the two previous layers an extra layer next to the fracture plane was found. This layer was $2-3 \mu \mathrm{m}$ thick with round rubber particles and no orientation of the matrix material. This indicates that, at the high deformation speed of the test, relaxation in the melt took place, suggesting that the material around the crack tip was molten during fracture.
\end{abstract}

(Keywords: nylon-rubber blend; strain rate effects; deformation)

\section{INTRODUCTION}

The impact behaviour of polyamide-polybutadiene (PA-PB) blends is dependent on material, morphology and test parameters ${ }^{1-11}$. A large stress-whitened zone can be seen on fractured samples, the structure of which has been studied by several groups ${ }^{7,12-17}$. On PA-rubber blends, Ramsteiner and Heckmann ${ }^{12}$ observed a thick layer with cavitated rubber particles and a smaller layer with cavities and shear bands next to the fracture surface. Borggreve $e t$ al. ${ }^{7}$ also observed cavitation of the rubber particles in the stress-whitened zone but no crazes. Speroni et al ${ }^{13}$ reported that the cavities were increasingly elongated as they lay nearer to the fracture plane. Oostenbrink et al.$^{14}$ noted the presence of three layers on tested notched Izod samples of blends of PA and ethylene-propylene rubber (EPR): a layer far from the fracture surface (0.10 to $2 \mathrm{~mm}$ ) with more or less round cavities, a layer nearer to the fracture plane ( 5 to $100 \mu \mathrm{m}$ from the fracture surface) with strongly elongated cavities and a $3-5 \mu \mathrm{m}$ layer next to the fracture plane without cavities.

It is well established that the cavitation takes place in the rubber particles ${ }^{12,15}$. A layer with strongly deformed cavities suggests strong plastic deformation of the matrix

* To whom correspondence should be addressed material. The absence of cavities in the layer next to the fracture surface on a tough broken sample suggests either that no cavities have been formed in this layer or that they have bcen formed during the fracture process but subsequently disappeared. A similar three-layer structure has been observed by Dijkstra and Gaymans $^{16}$ in notched tensile impacted PA-EPR samples tested at high test speeds $\left(1 \mathrm{~m} \mathrm{~s}^{-1}\right)$. On a partially fractured PA/ethylene-propylene-diene (EPDM) sample strained at low speeds, one sees elongated cavities ahead of the running crack $^{17}$. Dijkstra and co-workers ${ }^{11,16}$, when studying slowly deformed fractured samples' $\left(10^{-5} \mathrm{~m} \mathrm{~s}^{-1}\right)$, observed strongly deformed cavities up to the fracture plane.

The absence of (strongly deformed) cavities next to the fracture plane in samples deformed at high speeds suggests that cavities were formed ahead of the crack but subsequently disappeared in the region in front of and/or next to the crack. Cavitation can disappear if the surrounding matrix material relaxes. Large-scale relaxation in a semicrystalline polymer can only take place above the melting temperature. The cavities were found to disappear if the samples were heated to a temperature above the melting temperature of the $\mathrm{PA}^{16}$. This indicates that the layer without cavities has relaxed and that this relaxation has taken place in the melt. The presence of the relaxation layer suggests that at high test 
speeds the temperature in the fracture layer in these tough blends has risen above the melting temperature. The plastic deformation is largely dissipated as heat and under adiabatic conditions the strain necessary to obtain such a temperature rise is of the order of $350 \%{ }^{16}$. The formation of a melt layer in front of a crack might induce melt blunting of the notch and running crack ${ }^{16}$. Large temperature rises in the fracture plane of polymers have been reported by others ${ }^{18.19}$

The importance of melt layer formation in the fracture plane at high strain rates and the possible subsequent melt blunting process is so great that we had a closer look at the morphology of the deformation zone, with emphasis on the layer next to the fracture surface.

\section{EXPERIMENTAL}

Materials

The starting blend was a commercial nylon-6/polybutadiene blend (70/30) (Durethane BC303) supplied by Bayer. The blend was diluted with a high molecular weight nylon-6 (Akulon M258), supplied by DSM; $\eta_{\text {rel }}$ $\left(96 \% \mathrm{H}_{2} \mathrm{SO}_{4}\right)=5.8$ and $M_{\mathrm{n}}=35000 \mathrm{~g} \mathrm{~mol}^{-1}$. The rubber content in the studied samples was $\sim 1.5 \mathrm{vol} \%$

The blends were prepared on a Berstorff ZE $25 \mathrm{co}-$ rotating twin-screw extruder with a screw diameter of $25 \mathrm{~mm}$ and a length/diameter ratio of 33 . The compounding was carried out at a screw speed of $100 \mathrm{rev} \mathrm{min}^{-1}$, a barrel temperature of $260^{\circ} \mathrm{C}$ and a throughput of $2 \mathrm{~kg} \mathrm{~h}^{-1}$.

Specimens (Izod bars, according to ISO 180/1 A) were injection moulded on an Arburg Allrouder 221-55-250 machine. A notch was milled in the specimens, which were dried at $110^{\circ} \mathrm{C}$ under vacuum for $18 \mathrm{~h}$ before being tested

The rubber particle size (weight average) as measured by scanning electron microscopy (SEM) was $0.38 \mu \mathrm{m}$ and by transmission electron microscopy (TEM) was $0.30 \mu \mathrm{m}$ (Figure 1$)^{20}$. With SEM the smallest particles cannot be observed and this methods slightly overestimates the particle size.

The studied samples were fractured in a notched tensile set-up (as described in ref. 20) at crosshead speeds of $10^{-4}$ and $1 \mathrm{~m} \mathrm{~s}^{-1}$.

\section{Structure analysis}

Polarized light microscopy $(P L M)$. A small bar $(2.5 \times 1 \times 1.5 \mathrm{~mm})$ was cut from the middle of the fracture plane (Figure 2). The end of the bar (the fracture plane) was trimmed from three sides, with a glass knife at room temperature (RT), reducing the "fracture plane' dimensions to $500 \times 500 \mu \mathrm{m}$. This surface was then microtomed on a LKB Cryo Nova 2288-50 cryotome with a diamond knife, in the direction perpendicular to the fracture plane. Slices of $2 \mu \mathrm{m}$ thickness were cut at $-90^{\circ} \mathrm{C}$. They were collected on microscope slides and covered with a top glass. The slices were studied with a polarized microscope (Leitz-Ortholux II pol-BK).

Transmission electron microscopy, stained sections (TEM-SC). A small bar was obtained as described above, and stained in a $2 \%$ aqueous solution of $\mathrm{OsO}_{4}$ for $24 \mathrm{~h}$ at RT. The stained bar was embedded in epoxy resin (TAAB, resin 812 ) and cured at $35^{\circ} \mathrm{C}$ for 7 days.

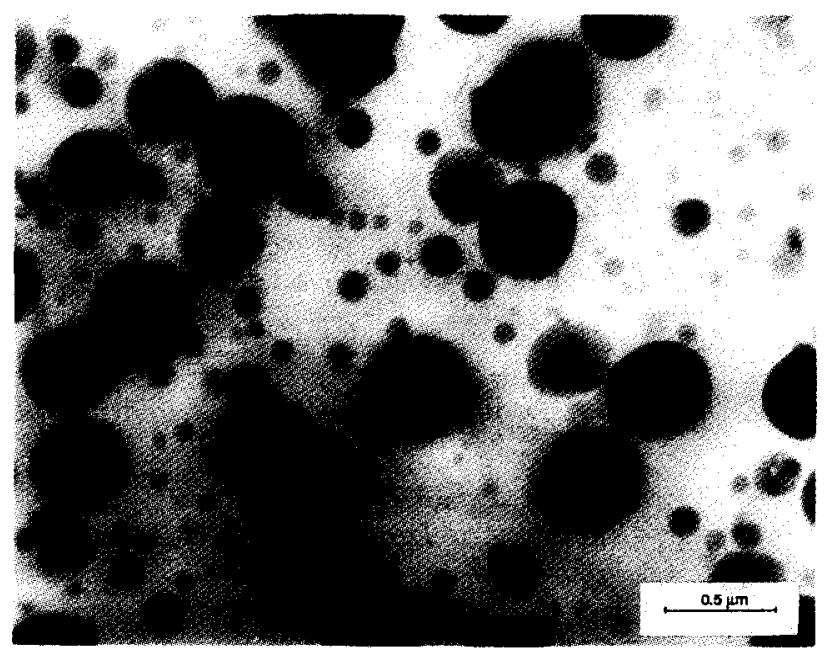

Figure 1 TEM micrograph of $\mathrm{OsO}_{4}$-stained $\mathrm{PA}-\mathrm{PB}$ blend ${ }^{20}$

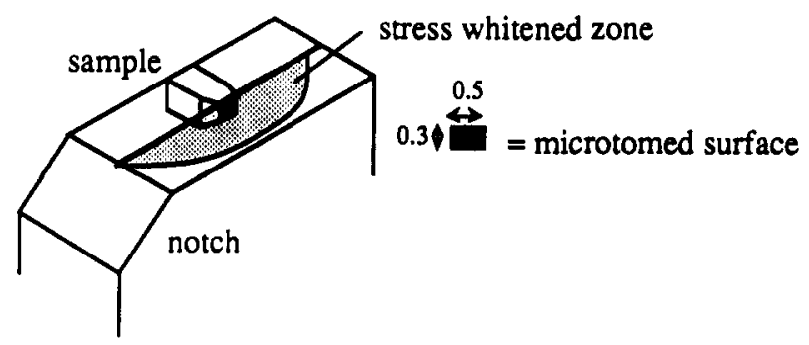

Figure 2 Specimen preparation from fractured sample. The dotted area is the microtomed surface

The embedded bars were first trimmed with a diamond knife at RT to a $400 \times 400 \mu \mathrm{m}$ 'fracture plane' and stained once more in $\mathrm{OsO}_{4}$ for $48 \mathrm{~h}$ at RT. Then they were trimmed to a $100 \times 50 \mu \mathrm{m}$ 'fracture plane'. The thus embedded, stained and trimmed samples were ultra-thin sectioned at RT in the direction perpendicular to the fracture plane. For TEM-SC, cuts of $60 \mathrm{~nm}$ were obtained with a 'wet' knife. The sectioning was carried out very carefully to avoid distortion of the cavitated structure. The slices were collected on 400 mesh microscope grids without a support film and studied with a Jeol $200 \mathrm{CX}$ transmission electron microscope (TEM), operating at $200 \mathrm{kV}$.

Transmission electron microscopy, selected area electron diffraction (TEM-SAED). On unstained embedded bars, slices were cryo sectioned at $-90^{\circ} \mathrm{C}$ and collected on 400 mesh microscope grids. The slices were studied with the TEM in the selected area electron diffraction mode. The TEM (Jeol-200 CX) was operated at $200 \mathrm{kV}$ with a very low dose setting of the electron beam (below $1 \mathrm{pA} \mathrm{cm}^{-2}$ ) and the stage cooled with liquid nitrogen. The camera length was $82 \mathrm{~cm}$. The TEMSAED pattern was obtained from the edge next to the fracture plane and some $20-30 \mu \mathrm{m}$ away from the edge. At a used magnification of $4000 \times$, the region giving rise to the diffraction pattern is $2 \mu \mathrm{m}$ in diameter. The patterns were taken as soon as the diffraction appeared but without final focusing. The SAED patterns were collected from at least 20 places for every sample.

Polymers are electron beam sensitive and, as a result, diffraction patterns decay very rapidly. Therefore all the 
samples were studied under identical conditions and the sample areas were not pre-exposed.

Transmission electron microscopy, carbon replica $(T E M-C R)$. The surface was covered with a $5 \%$ solution of poly(vinyl alcohol) (PVA). After drying, the PVA film was pecled off, shadowed with platinum and covered with carbon. Subsequently the PVA was dissolved and the $\mathrm{Pt} / \mathrm{C}$-replica was examined with the TEM. This technique was also used for studying the fracture plane.

Scanning electron microscopy. An embedded sample was cryo fractured, sputtered with a layer of gold and studied with a Hitachi $\mathbf{S} 800$ scanning electron microscope (SEM).

\section{RESULTS}

Injection moulded PA-6/polybutadiene blend (85/15) samples were fractured according to the notched tensile $\operatorname{method}^{20}$. The studied samples were tested at a low crosshead speed of $10^{-4} \mathrm{~m} \mathrm{~s}^{-1}$ (L) and at a high crosshead speed of $1 \mathrm{~m} \mathrm{~s}^{-1}(\mathrm{H})$. The high speed test corresponds to the loading rate in the notched Izod and notched Charpy methods. The fracture energy of the materials is $230 \mathrm{~kJ} \mathrm{~m}^{-2}$ at $10^{-4} \mathrm{~m} \mathrm{~s}^{-1}$ and $190 \mathrm{~kJ} \mathrm{~m}^{-2}$ at $1 \mathrm{~ms}^{-1}$ (ref. 20).

Both the $\mathrm{L}$ and $\mathrm{H}$ samples show a strong stresswhitening zone next to the fracture plane (in the middle of the sample) with a thickness of 2.5 and $1 \mathrm{~mm}$, respectively.

\section{Polarized light microscopy}

The PLM results were obtained with a polarizer and analyser not completely crossed $\left(5^{\circ}\right.$ ofl $)$. The maximum birefringence was observed for samples placed with the fracture edge parallel to a polarizer. For the $\mathrm{L}$ sample the birefringence increases as the fracture surface is approached (Figure 3a), with highest birefringence being observed at the fracture surface. This means that the orientation in the $\mathbf{L}$ sample increases as the fracture surface is approached.

In the $\mathrm{H}$ sample also, the birefringence increases as the distance to the surface decreases (Figure $3 b$ ). However, directly next to the fracture surface, a thin nonbirefringent layer $\sim 2 \mu \mathrm{m}$ thick can be observed (on the black and white photo this layer is nearly dark). These results suggest that the orientation in the $\mathrm{H}$ sample increases as the fracture surface is approached; however, next to the fracture surface an unoriented layer is present (thickness $\sim 2 \mu \mathrm{m}$ ).

\section{TEM-stained cuts}

The structure of the undeformed blend is shown in Figure 1. The TEM-SC micrograph of the L sample shows a cavitated structure $2.5 \mathrm{~mm}$ away from the fracture plane. The cavities are in the bigger rubber particles (Figure 4a); cavitation of smaller particles seems to be more difficult, with a lower limit of $0.1 \mu \mathrm{m}$. A particle size effect on the ease of cavitation was observed earlier $^{2,9,15,21}$ and has been modelled ${ }^{22}$. Next to the fracture plane the particles are strongly elongated, having a length/diameter $(L / D)$ ratio of $5-10$, and these are observed up to the fracture surface (Figure
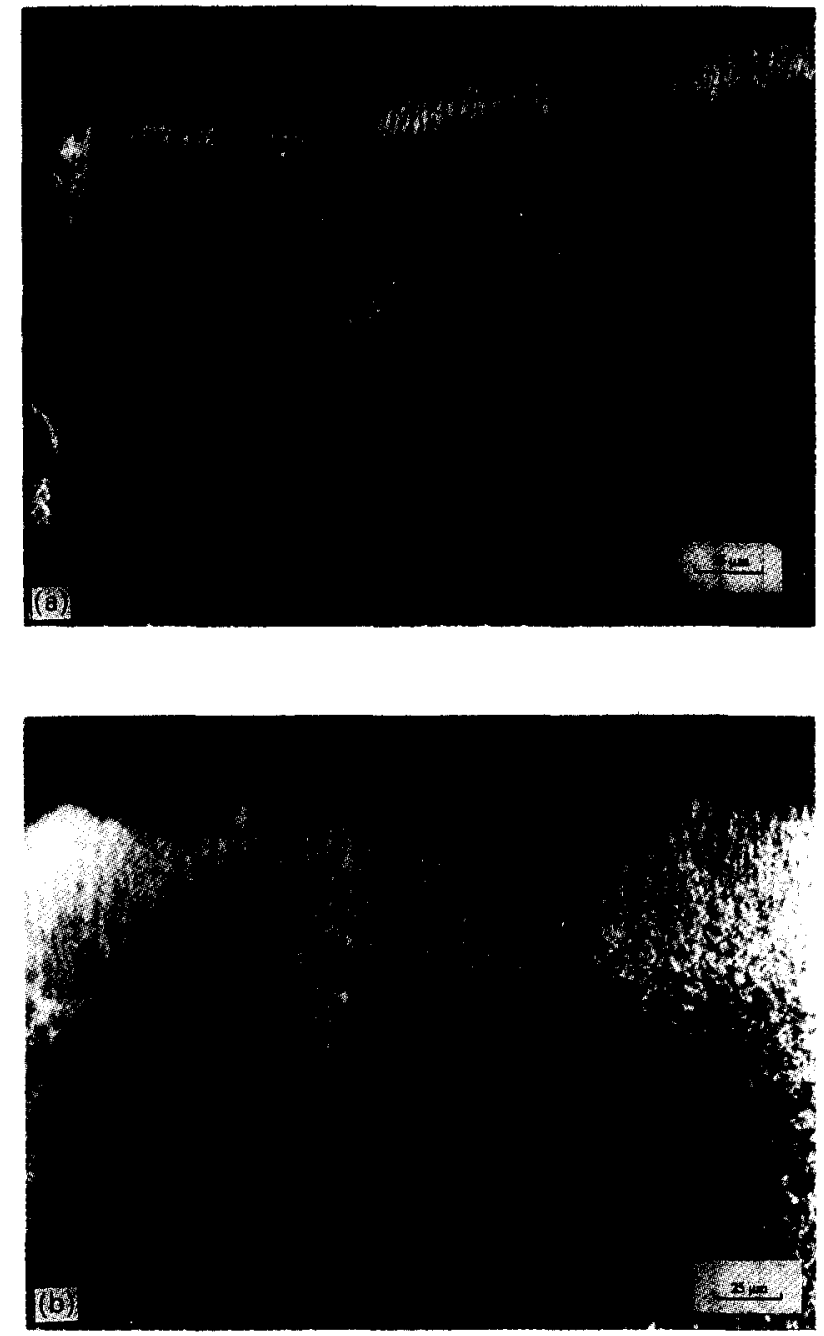

Figure 3 Polarized light micrographs of deformed blends perpendicular to the fracture plane: (a) L sample; (b) H sample

$4 b$ ). The orientation angle of the particles is $\sim 45^{\circ}$ to the fracture surface.

For the $\mathrm{H}$ sample, a cavitated structure (Figure $5 a$ ) was observed far from the fracture plane $(1 \mathrm{~mm})$, similar to that in the L sample (Figure $4 a$ ). Next to the fracture plane a complicated morphology can be seen (Figure $5 b$ ). Strongly elongated particles can be observed up to $3 \mu \mathrm{m}$ to the fracture surface, the $L / D$ ratio of the particles being $3-5$ and the orientation $\sim 45^{\circ}$. Next to the fracture surface the elongation disappears and a $2-3 \mu \mathrm{m}$ layer of round rubber particles can be seen. This suggests that in the $\mathrm{H}$ sample the matrix material next to the fracture surface has relaxed.

\section{$T E M-S A E D$}

To study the matrix deformation and relaxation in the stress-whitened layer, the samples were analysed with TEM-SAED. It is expected that the PA-6 is partially in the $\gamma$ - and partially in the $\alpha$-structure. The electron diffraction pattern of an undeformed sample shows a ringed structure (Figure 6a). Only one ring is observed for the $d_{200}$ and $d_{002}$ spacings, but the resolution of this method is not sufficient to observe the expected peak splitting.

In the $\mathrm{L}$ sample far from the fracture surface $(20-$ $30 \mu \mathrm{m})$ a ringed structure can be observed (Figure $6 \mathrm{~b}$ ), 

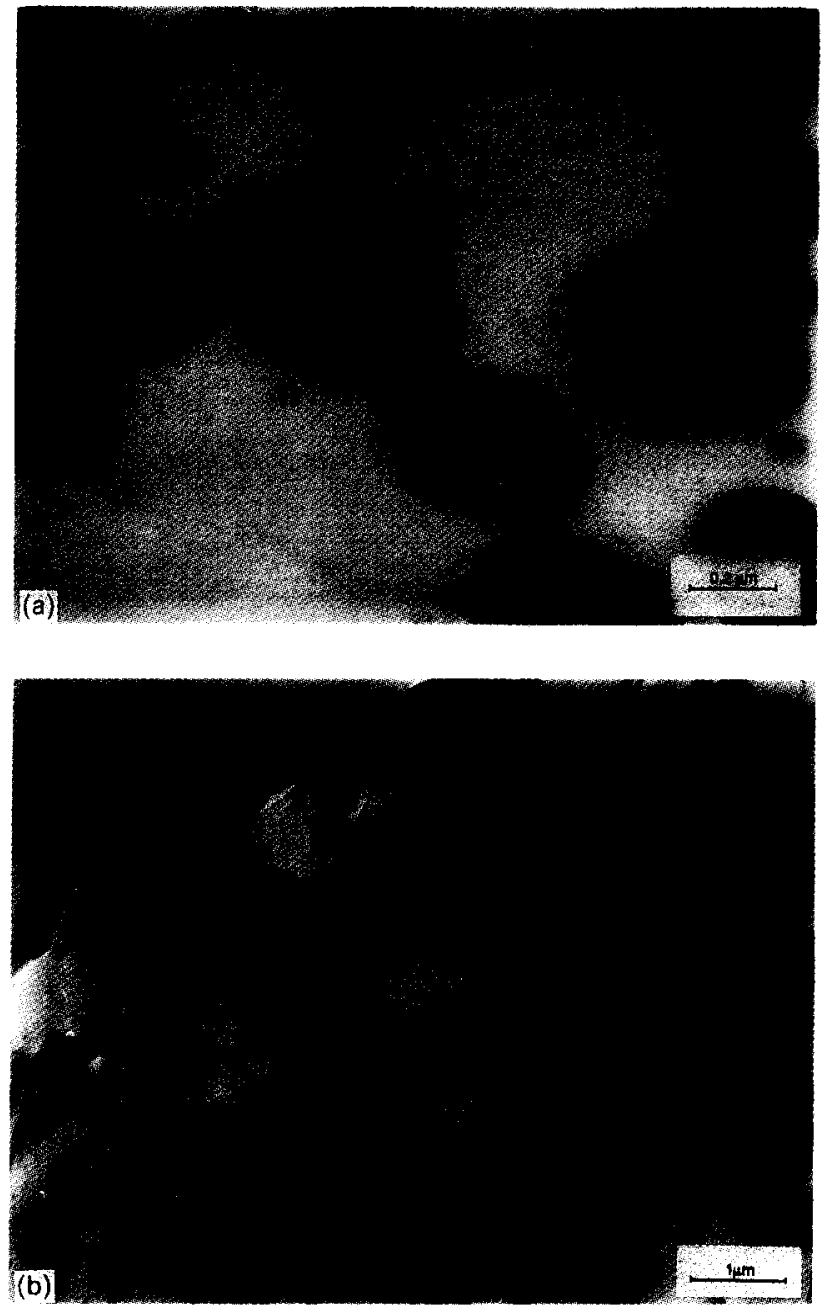

Figure 4 TEM micrographs of stained cuts from sample L: (a) far from fracture plane $(2.5 \mathrm{~mm})$; (b) next to fracture plane

suggesting a high crystallinity without orientation. The diffraction pattern taken next to the fracture surface of the $\mathrm{L}$ sample shows an arc pattern (Figure $6 \mathrm{c}$ ). This clearly indicates that next to the fracture plane the PA-6 is highly crystalline and oriented.

The diffraction pattern of the $\mathrm{H}$ sample at $20-30 \mu \mathrm{m}$ from the fracture surface is composed of rings (Figure $6 d$ ) as observed in the L sample (Figure $6 b$ ). The diffraction pattern of the $\mathrm{H}$ sample next to the fracture surface (2 $3 \mu \mathrm{m}$ layer) is a vague ring (Figure 6e), suggesting a low order of the PA-6 and random orientation. Compared with the $\mathrm{L}$ sample, the material in the fracture plane of the $\mathrm{H}$ sample has lost both its orientation and order. Loss of orientation and order clearly indicate that this material has relaxed in the melt and was fast cooled from the melt.

\section{SEM-cryo fracture}

An embedded, unstained $L$ sample was fractured in liquid nitrogen perpendicular to the fracture plane. Strongly deformed cavities can be seen right up to the fracture surface with an $L / D$ radio of $5-10$ and an orientation angle to the fracture surface of $\sim 45^{\circ}$ (Figure 7). In this micrograph the cavities can be seen more clearly than in the TEM-SC on thin slices.
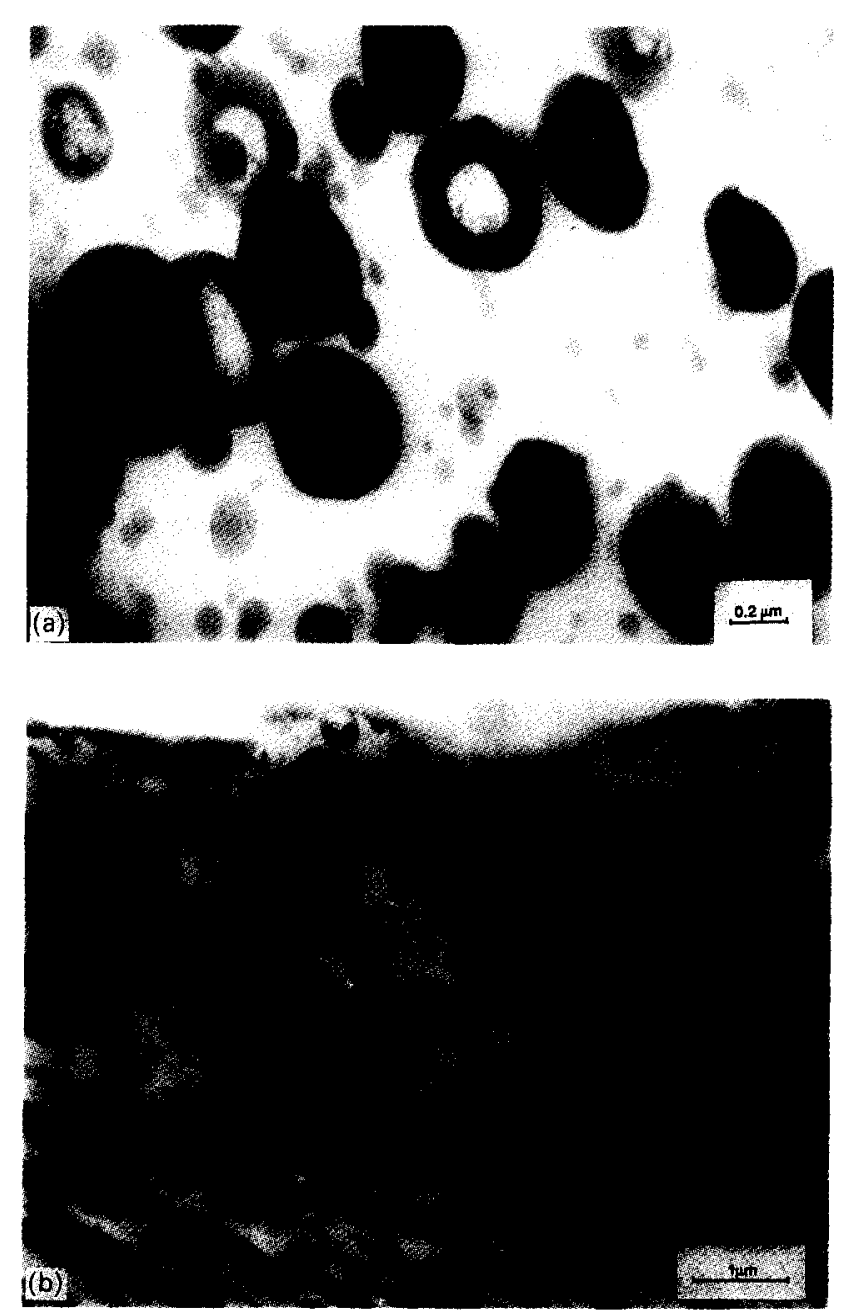

Figure 5 TEM micrographs of stained cuts from sample H: (a) far from fracture plane $(1 \mathrm{~mm})$; (b) next to fracture plane

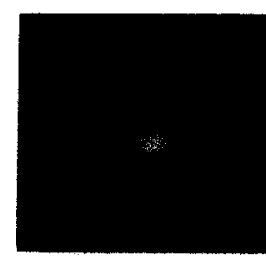

(a)

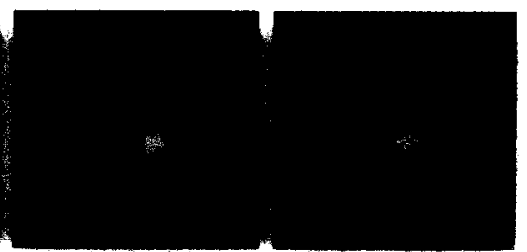

(b)

(c)

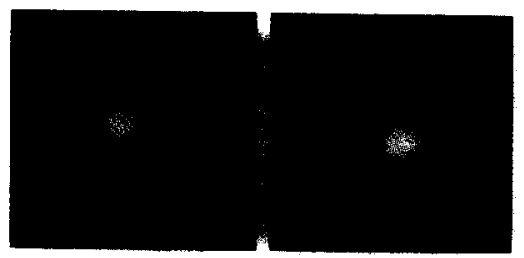

(d)

(e)

Figure 6 TEM-SAED patterns of microtomed films: (a) undeformed material: (b) sample L, 20-30 $\mathrm{m}$ from fracture plane; (c) sample L next to fracture plane; (d) sample $\mathrm{H}, 20-30 \mu \mathrm{m}$ from fracture plane; (e) sample $H$, next to fracture plane

\section{TEM-CR fracture surface}

Fracture surface replicas wcre made and studied by TEM. On the $\mathrm{L}$ sample small round heterogeneities with a size of $0.04-0.08 \mu \mathrm{m}$ (Figure $8 a$ ) can be seen. The size corresponds to the diameter of the elongated cavities in 


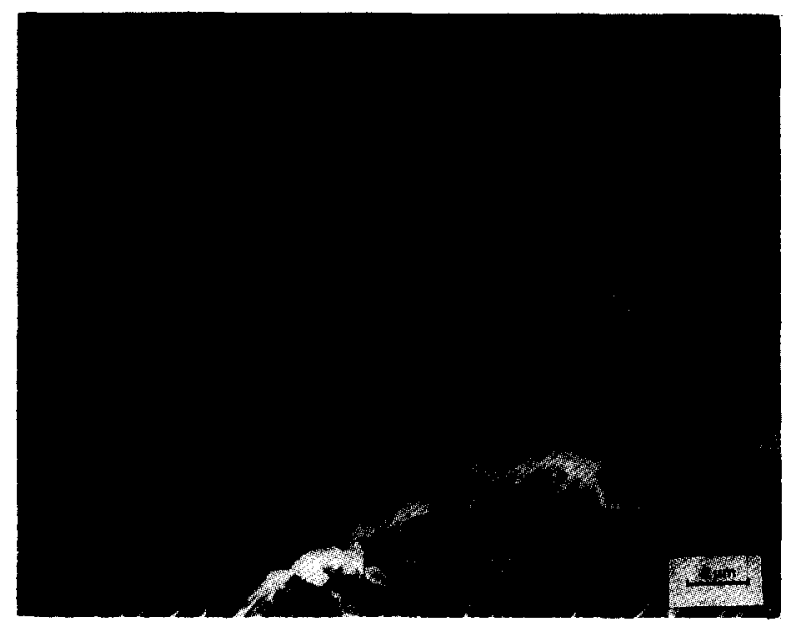

Figure 7 SEM micrograph of embedded, unstained L sample, cryo fractured: next to fracture plane
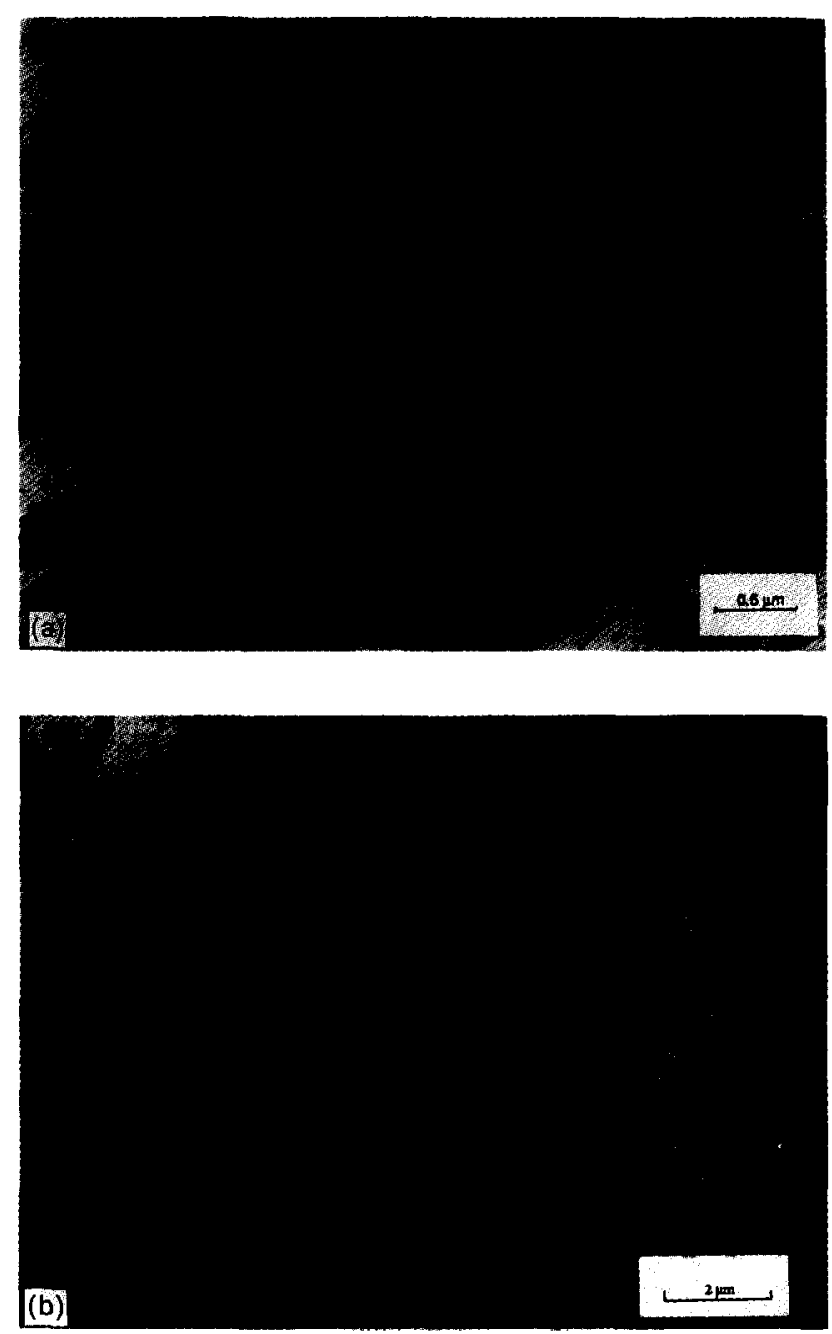

Figure 8 TEM-CR of fracture plane of deformed samples: (a) $L$ sample; (b) $\mathrm{H}$ sample

Figure 7. Round particles can also be seen on the $\mathrm{H}$ sample but they of a larger size, $0.25-0.5 \mu \mathrm{m}$ (Figure $8 \mathrm{~b}$ ). This corresponds to the size of the round particles in the relaxed layer next to the fracture surface (Figure 5).
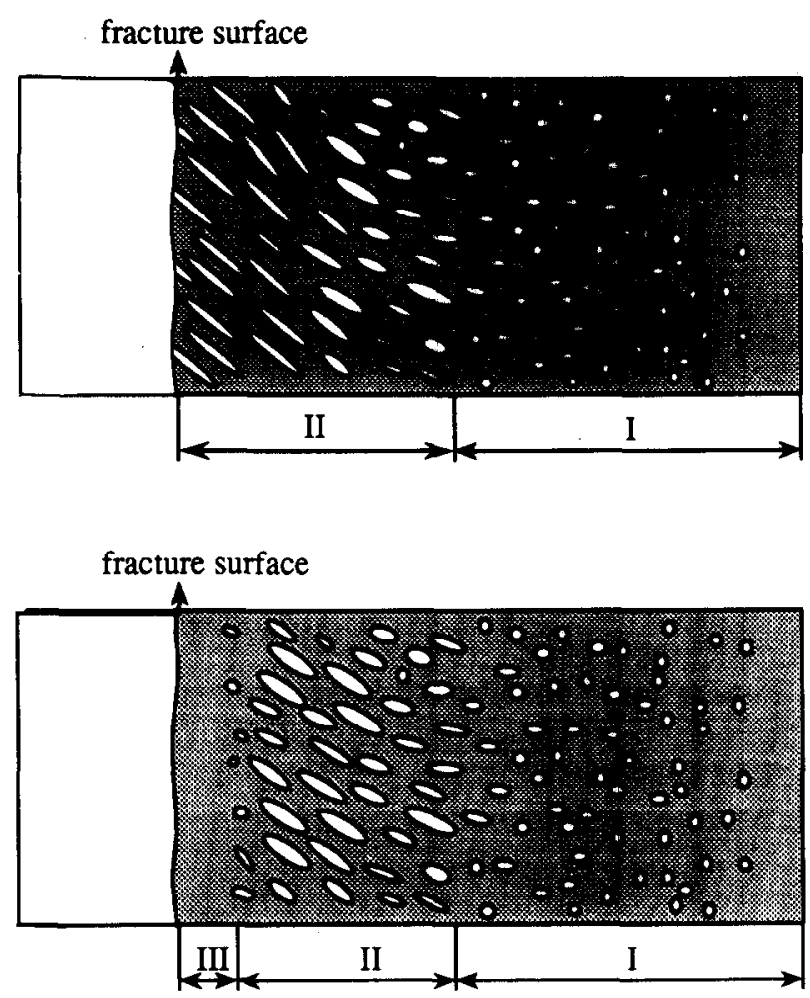

Figure 9 Schematics showing structure of stress-whitened zone perpendicular to the fracture planc: (a) L sample; (b) II sample. I, cavitation layer; II, deformation layer; III, melt layer

\section{CONCLUSIONS}

Tough fractured samples of PA-rubber blends show a strong stress-whitened zone next to the fracture plane. In samples tested at $10^{-4} \mathrm{~m} \mathrm{~s}^{-1}$ this zone was found to comprise two layers: far from the fracture plane cavitation of the rubber particles (Figure $4 a$ ) with no orientation of the matrix material was observed (Figure $6 b$ ), while next to the fracture plane a structure with strongly elongated cavities (Figures $4 b, 7$ ) and oriented matrix material was found (Figures $3 b, 6 c$ ). These results correlated with earlier SEM results on PA-EPR ${ }^{11}$. A schematic drawing of this two-layer structure is given in Figure $9 a$.

The stress-whitened zone in samples tested under impact conditions $\left(1 \mathrm{~m} \mathrm{~s}^{-1}\right)$ was found to have a threelayer structure. Far from the fracture plane only cavitation of rubber particles was visible (Figure 5a) and no orientation of the matrix (Figure $6 d$ ). Nearer to the fracture plane the material became more oriented (Figure $3 b$ ) and strongly elongated cavities were present (Figure $5 b$ ). Next to the fracture plane there was a 2$3 \mu \mathrm{m}$ layer consisting of round rubber particles (Figure $5 b$ ) and matrix (Figure $3 b$ ) with no orientation and a poorly developed crystalline structure (Figure $6 e$ ). These results correlate with earlier SEM results on PA-EPR samples subjected to notched notch tensile ${ }^{11,15}$ and Izod $^{13}$ tests. A schematic drawing of this three-layer structure is given in Figure $9 b$

The main difference between the samples is that in the L samples a two-layer structure is present and the material within the fracture plane is highly oriented. In the $\mathrm{L}$ samples the maximum orientation is also higher. In the $\mathrm{H}$ samples an unoriented layer is present next to the fracture surface. The matrix material in this unoriented layer had a poorly developed crystalline structure and 
the rubber particles were round again. It is known that orientation in semicrystalline materials relaxes in the melt. This has been confirmed by oil bath experiments on deformed (cavitated) samples ${ }^{16}$ : the cavities in the blend were found to disappear at the melt temperature. In the $\mathrm{H}$ sample melt relaxation has clearly taken place, which means that during the fracture at high speeds a melt zone must have been present around the crack tip. An explanation for this melting is that the deformation becomes adiabatic at high speeds and, owing to the plastic deformation under these conditions, the heat generation is high enough for melting to take place ${ }^{16}$. The high impact strength of these blends at very high speeds seems to be due to the presence of this melt zone in front of the crack. Thus at high loading rates melt blunting takes place.

Similar 'melt layers' have been observed in polypropylene-EPDM blends $s^{23}$ and acrylonitrile--butadiene styrene copolymer ${ }^{24,25}$.

\section{ACKNOWLEDGEMENT}

This work is part of the research programme of the University of Twente. H. Janik was financially supported by the EEC programme for Cooperation in Science and Technology with Central and Eastern European Countries, Grant no. ERB3510PL921508.

\section{REFERENCES}

1 Dijkstra, K. PhD Thesis, University of Twente. The Netherlands, February 1993

2 Dijkstra, K. and Gaymans, R. J. Pollmer 1994, 35, 333

3 Oshinski, A. J., Keskkula, H. and Paul, R. D. Polymer 1992, 33, 268
Oshinski, A. J., Keskkula, H. and Paul, R. D. Polvmer 1992, 33 284

$5 \quad$ Borggreve, R. J. M., Gaymans, R. J. and Schuijer, J. Polymor $1989,30,71$

6 Borggreve, R. J. M. and Gaymans, R. J. Polymer 1989, 30, 63

7 Borggreve, R. J. M., Gaymans, R. J., Schuijer, J. and Ingen Housz, J. F. Polymer 1987, 28, 1489

$8 \quad$ Wu, S. Polymer $1985,26,1855$

9 Oostenbrink, A. J., Molenaar, L. J. and Gaymans, R. J. 'Preprints, Polymer Blends Conference', Cambridge, 1990, Paper E3.

10 Lazzeri, A. PhD Thesis, Cranfield Institute of Technology, UK, 1991

11 Dijkstra, K. van der Laak, J. and Gaymans, R. J. Polymer 1994, 35, 315

12 Ramsteiner, F., and Heckmann, W. Polym. Commun. 1985, 26, 199

13 Speroni, F., Castoldi, E., Fabbri, P. and Casiraghi, T. J. Mater. Sci. $1989, \mathbf{2 4}, 2165$

14 Oostenbrink, A. J., Dijkstra, K., van der Wal, A. and Gaymans, R. J. 'Preprints, Deformation and Fracture of Polymers', Cambridge, April 1991, Plastics and Rubber Institute, London, Paper 50

15 Dijkstra, K., van der Wal., A. and Gaymans, R. J. J. Mater. Sii. $1994,29,3489$

16 Dijkstra, K. and Gaymans, R. J. J. Mater. Sci. 1994, 29, 3231

17 Gaymans, R. J. and Borggreve, R. J. M. in 'Contemporary Topics in Polymer Science, Vol. 6' (Ed. B. M. Culbertson), Plenum Press, New York, 1989, p. 461

18 Godovsky, Y. K. 'Thermophysical Properties of Polymers', Springer Verlag, München, 1992, p. 252

19 Kambour, R. P. and Baker, R. E. J. Polym. Sci., Part A-2 1966. 4, 359

20) Dijkstra, K., Wevers, H. H. and Gaymans, R. J. Polymer 1994. 35, 323

21 Dijkstra, K. and Gaymans, R. J. Polymer 1994, 35, 333

22 Lazzeri, A. and Bucknall, C. B. J. Mater. Sci. 1993, 28, 6799

23 Wal, A. and Gaymans, R. J. 'Preprints, ACS PMSE San Diego Meeting', American Chemical Society, Washington, DC, 1994, p. 191

24 Steenbrink, A. C., Gaymans, R. J. and van der Giesen, E. 'Materials Institute Polymat '94' London, September 1994, p. 598

25 Steenbrink, A. C., Janik, H. and Gaymans, R. J. to be published 